\title{
Constituição do sujeito na formação de professores: significação nas práticas cotidianas
}

Subject's constitution in teacher education: signification in everyday practices

Susana Inês Molon*

Universidade Federal do Rio Grande

Resumo Este trabalho discute noções de sujeito, experiência, processos de significação e práticas cotidianas. Partindo da concepção de que o sujeito é constituído nas e pelas mediações semióticas, implicados na dimensão histórica e cultural, sem perder a singularidade e focando os processos de significação, realizou-se a análise de entrevistas com seis professores a partir das contribuições de Bakhtin, Thompson e Vygotsky. As análises evidenciam que os processos de se constituir professores são perpassados pela formação inicial; pela formação continuada; pela atuação docente nas experiências em sala de aula por meio do vínculo entre teoria e prática; e pelas mudanças na prática pedagógica. Além disso, estão presentes escolhas e valores, individuais e coletivos, que expressam questões de gênero e de classe social na formação inicial e continuada de professores.

PALAVRAS-CHAVE: Constituição do sujeito; Processos de significação; Formação continuada de professores.

Abstract This study discusses notions of subject, experience, signification processes and everyday practices. Taking into account that the subject is constituted by and in semiotic mediation, which is embedded in a historical and cultural dimension, keeping its singularity and focusing on signification processes, the analysis of interviews made with six teachers and based on Bakhtin's, Thompson's and Vygotsky's contributions was carried out. The analyses showed that the processes of teachers' constitution rely on early education; continuing education; teaching experience in class based on the connection between theory and practice; and changes in pedagogical practices. These aspects are based on choices and values, both individual and collective ones, which express issues related to gender and social class in early and continuing teacher education.

KEYWORDS: Subject's constitution; Signification processes; Continuing teacher education. 


\section{Introdução}

Uma das contribuições de Mikhail Bakhtin na compreensão da constituição do sujeito no enfoque histórico-cultural está na argumentação sobre o fato de o sujeito individual viver um "não-álibi na existência", isto é, cada um de nós ocupa um lugar singular e único. Outra colaboração bakhtiana encontra-se na compreensão da relação entre o mundo experimentado pela ação e o mundo representado no discurso. Na obra Para uma filosofia do ato responsável, Bakhtin (2010) está problematizando, entre outras coisas, a experiência e a representação da experiência, ou seja, buscando compreender a diferença entre atos que são sentidos como únicos na sua realização "evento único do ser" e as consequências de tais eventos. Ele reconhece a diferença entre a experiência vivida - o acontecer na vida -, o ato vivido, a ação e as consequências do que aconteceu (a representação do "mesmo" ato, o relato do acontecido, o significado da ação), que formam um amálgama que está vinculado com a relação do que o sujeito forma entre elas em toda a singularidade do seu lugar único na existência. A unidade de um ato e seu relato, uma ação e seu significado, é um processo complexo, que exige responsabilidade, que precisa estabelecer uma relação entre ambos, sendo esta imprevisível, não definida a priori.

Essa discussão explicitada por Bakhtin (1992a; 1992b; 2010) encontra densidade nas elaborações conceituais de Vygotsky $(1998 ; 2001)$ e de autores do enfoque histórico-cultural, dentre eles Góes (2000), Góes e Smolka (1997), Góes, Smolka, e Pino (1998), Molon (2003; 2009), Pino (2005; 2006) e Smolka (2004; 2006a; 2006b). A questão da significação ganha centralidade nesses autores que priorizam a compreensão da dimensão semiótica; mais precisamente, indagam sobre as condições de emergência e de possibilidades de produção da significação.

Assim, não é a ação, não é a atividade prática, não é a dimensão biológica que constituem o sujeito, mas a significação, a produção material, de natureza social, de signos. Os signos são resultantes das e nas relações sociais, na história da e na produção humana. O princípio da significação possibilita compreender a conversão das relações sociais em funções psicológicas (VYGOTSKY, 2000), ou seja, compreender o desenvolvimento histórico-cultural dos sujeitos.

Portanto, o fato de não existir álibi para a experiência humana significa dizer que essa experiência, apesar de única e irrepetível, acontece no social, na história das e nas relações sociais de produção. No processo de significação, as apropriações únicas de cada um constituem processos de subjetivação que encontram ressonância em um tempo e em um lugar específico, com determinadas condições materiais de produção.

Para Bakhtin (2010), a assinatura de cada experiência vivida, cada pensamento, sentimento e gesto deve ser um ato ou ação responsável no mundo da realidade; porém, essa assinatura não é expressão de uma subjetividade indelével, indizível e inefável, mas sim de uma posição, de uma singularidade inscrita na relação com o outro, em um dado espaço-tempo, em um contexto de confronto e conflito com os outros sujeitos. 
Cabe ressaltar que essa noção bakhtiana não se aproxima das concepções solipsistas, subjetivistas e introspectivas; muito pelo contrário, sua obra apresenta como eixo central a questão da alteridade (AMORIN, 2009; GERALDI, 2003). Desse modo, o processo de constituição do sujeito acontece nas e pelas relações sociais, nas e pelas mediações semióticas (MOLON, 2009). O outro é a condição sine qua non do sujeito. Assim, o foco são as relações Eu-Outro, ou seja: "O outro, portanto, é condição do eu, do unívoco que, socialmente constituído, não se eclipsa em supostas homogeneizações, porém necessariamente se faz um na relação com esse(s) outro(s)" (ZANELLA e MOLON, 2007, p. 59).

E partindo desse pressuposto que se adentra na discussão sobre o conceito de experiência, concebendo-a nas suas dimensões histórica, social e duplicada, tal como explicitada por Vygotsky (1996) e compreendida, também na sua dimensão singular, por Bakhtin (2010) e Thompson (1981). Aqui, a experiência está articulada à consciência. A consciência procede da experiência. A experiência histórica e a social são indissociáveis e potencializam a duplicada e a singular.

Thompson (1981) enfatiza a importância das experiências dos sujeitos históricos (os excluídos) e do mundo em que viviam, entendendo que ali estão presentes as contradições, as lutas, as resistências e as ressignificações das experiências cotidianas vividas na história cultural. Assim, estabelece um ponto de junção entre a experiência e a cultura, que possibilita a consciência afetiva e moral, pois considera que as pessoas nessa relação "experimentam sua experiência como sentimento e lidam com esses sentimentos na cultura, como normas, obrigações familiares e de parentesco, e reciprocidades, como valores [...] na arte ou nas convicções religiosas" (THOMPSON, 1981, p. 189).

Dessa maneira, os sujeitos estabelecem conflitos e escolhas de valor, sempre, mesmo que social e culturalmente determinados. Por isso, é necessário compreender na relação entre a experiência e a cultura como os sentimentos, os valores, as convicções, enfim, as apropriações e as práticas culturais estão sendo vividas pelos sujeitos históricos pertencentes a um determinado lugar que ocupam determinadas posições sociais.

Como esclarece Smolka (2006a, p. 107), "experiência é resultante daquilo que impacta e é compreendido, significado, pela pessoa. Há um aspecto compreensivo, apreciativo, valorativo nos sentidos da situação vivida. Não existe experiência sem significação" (grifos da autora). Portanto, a experiência é significada e sentida no e pelo sujeito. A vida é repleta de sentidos, e os indícios e os vestígios constituem fenômenos psicológicos significativos (VYGOTSKY, 1995). Assim, é preciso compreender as experiências residuais que emergiram pela significação. A significação envolve o contexto extraverbal em que o enunciado foi produzido, ou seja, o dito vincula-se ao não dito, o texto ao intertexto, ao extratexto e ao subtexto.

Os conceitos de experiência, trabalhados por Vygotsky, Bakhtin e Thompson, são fundamentais para entender as posições, os lugares e as ações dos sujeitos, já que propiciam a compreensão dos conflitos, das resistências, das contradições, das 
incertezas, das lutas, considerando a interconstituição das dimensões racionais e emocionais, singulares e históricas, individuais e coletivas, sociais e culturais, objetivas e subjetivas, bem como os diversos valores e as diferentes visões de mundo, que configuram o drama dos sujeitos, seus modos de ser e suas maneiras de fazer na vida cotidiana.

$\mathrm{Na}$ complexa e contraditória trama da vida (diversas experiências, múltiplos outros em várias posições sociais, diferentes valores, diversas bases afetivo-volitivas), os sujeitos experienciam seus dramas, de modo singular, considerando as significações produzidas na trama das relações intersubjetivas. Assim, apropriam-se dos significados e produzem (junto com os outros) sentidos de seus inacabamentos, suas incompletudes, suas (im)possibilidades de se constituírem mutuamente e reciprocamente em uma organização semiótica nas dinâmicas dialógicas e nas práticas sociais em um determinado contexto.

\section{O método de pesquisa e os procedimentos metodológicos}

A presente investigação fundamenta-se no enfoque histórico-cultural. $\mathrm{O}$ trabalho de campo foi possibilitado pela intervenção e atuação nas atividades de formação continuada de um grupo de professores e pela realização de entrevistas semiestruturadas com seis professores.

A trama da dinâmica intersubjetiva e discursiva urdida e tecida nos encontros em uma escola municipal foi proporcionada também pelo diálogo e pela alteridade vivenciada nas relações intersubjetivas, cujo foco das discussões e das argumentações girava em torno da prática docente, das aventuras e dos desassossegos experimentados pelos diferentes sujeitos que ocupam diversas posições e diferentes lugares no contexto escolar.

Para elaborar os eixos orientadores da entrevista semiestruturada, partiu-se de uma questão de pesquisa, qual seja: como os professores que participam da formação continuada significam as experiências provocadas na formação inicial e no grupo de formação continuada e como se constituíram professores? Dentro disso, alguns questionamentos emergiram: como se apropriam dos saberes e dos conhecimentos e como os incorporam nas suas práticas? Como essas práticas estão relacionadas ao desenvolvimento dos processos de constituição dos sujeitos e à emergência de novas formas de atividade e de novas práticas pedagógicas?

Cabe esclarecer que, no enfoque histórico-cultural que fundamenta o estudo, os dados de pesquisa não são considerados como discursos em si, mas como signos que adquirem sentidos e significados nas relações intersubjetivas dos sujeitos envolvidos, pesquisadores e pesquisados, localizadas em uma época, em um tempo, em um contexto, com suas vicissitudes e circunstâncias, com suas posições e lugares sociais e ideológicos.

A análise de conteúdo (FRANCO, 2007) das entrevistas dos professores por meio das narrativas das experiências de formação e atuação docente, tendo como foco os primeiros anos de docência e a busca pela formação continuada, é compreendida a partir do e no contexto formativo, nos meandros das relações intersubjetivas e das 
práticas cotidianas. É considerando esse lugar, esse tempo e esse espaço que se compreende os processos de constituição do sujeito e da subjetividade, bem como os meandros das relações intersubjetivas dos professores, procurando nas suas singularidades as condições culturais e históricas que perpassam o tornar-se professor. Compreendendo que "sendo o que somos, somos também a negação do que não somos e, nesse sentido, o que não somos também nos constitui, está em nós. Ser e também não ser: aí radica e é produzida a singularidade" (FONTANA, 2000, p. 105).

A narrativa permite que se fale o que somos e o que não somos e, ao mesmo tempo, se reconstrói a memória do vivido, fazendo com que o sujeito possa ressignificar suas vivências, seus modos de atuação, de pensar, de sentir, de dizer, de olhar para si e para o outro. Porém, não buscando a coerência, a regularidade, literalidade e a linearidade do acontecido, mas defrontando-se com a insegurança, com o silêncio, com as incertezas, com o instável, com a frustração, com o contraditório, com as insignificâncias significativas, com as escolhas feitas pelos outros e (posteriormente) por si mesmo, com os múltiplos e diversos outros que o constituem em "Homo Multiplex" (SMOLKA, 2004), já que o sujeito é "o conjunto de relações sociais, encarnado no indivíduo"(VYGOTSKY, 2000, p. 33).

Nessa linha de argumentação, Bakhtin (1992b) considera que aquilo que o sujeito narra de si mesmo deve ser compreendido na polifonia de vozes e na intertextualidade implicada na construção discursiva, pois o discurso nunca é solitário e individual, ou seja, "sem a narrativa dos outros, minha vida seria não só incompleta em seu conteúdo, mas também internamente desordenada, desprovida dos valores que asseguram a unidade biográfica" (BAKHTIN, 1992b, p. 169).

Assim, tendo presente a complexidade das vivências, dos papéis sociais e das diversas condições e posições que constituem os dramas dos sujeitos, implicados nas tramas tecidas pelas experiências de múltiplos outros, pelas múltiplas vozes e pelos diversos valores e sentimentos, enfoca-se as análises das experiências de formação e de atuação docente dos entrevistados e os meandros das relações intersubjetivas e das práticas cotidianas em contextos de ensinar e aprender.

\section{Escolhas, valores, questões de gênero e de classe na formação inicial}

$\mathrm{Na}$ narrativa dos professores pesquisados, aparece a questão do magistério e da prática docente, da presença e atuação feminina na formação docente. A opção pelo magistério traz a forte presença da figura materna - a mãe - nessa escolha. Como diz Thompson (1981), existe um ponto de junção entre a experiência e a cultura. Assim, os sujeitos estabelecem conflitos e escolhas de valores nas suas decisões, que são social e culturalmente determinados. Aqui reside uma questão de gênero e de classe social (mulheres das classes menos favorecidas). Ainda como observa Thompson (1981), os valores, as normas, as regras, as expectativas são aprendidas, sentidas e vividas na família, na comunidade e no trabalho, sempre um terreno de contradição, de luta entre valores e pontos de vista, como pode ser observado nas falas dos sujeitos pesquisados. 
Três entrevistadas dizem explicitamente que foram obrigadas pela mãe a fazer magistério. Uma delas salienta a valorização do estudo para a "família simples da roça" e o papel que deve ser desempenhado pela mulher na sociedade, o cuidar de criança, ficar junto com a família (não poderia escolher uma faculdade longe dos parentes) e o ser professora, sendo que sua mãe trabalhava na secretaria de uma escola.

$\mathrm{Na}$ sua trajetória, a professora ressalta a resistência pessoal, fez a contragosto, e justifica sua reação, a briga com a família pela inquietação adolescente. Percebe-se que essa situação vivida pela professora traz a dimensão histórica e social da experiência de ser "mulher pobre da roça", que ultrapassa os valores ensinados pelos pais, pois, como diz Vygotsky (1996), são experiências de gerações anteriores que estabelecem conexões e tensões com as experiências atuais, circunscrevendo práticas culturais de uma determinada comunidade, no caso, família de classe social desfavorecida da zona rural.

Nesse choque de valores e de interesses, tanto na zona rural quanto na zona urbana, acontecem avanços e retrocessos. Uma das professoras que vivem na cidade, ao mesmo tempo em que reconhece o papel da mãe/mulher na opção profissional, diz que para sermos professoras não basta gostarmos de crianças. Constata-se aí uma superação de outra noção ligada à figura feminina na atividade docente, que é o fato de gostar de crianças.

Uma outra entrevistada também fala da determinação da família na opção pelos estudos (a mãe decidiu e o pai fez cumprir), não considerando a vontade dela e sua dedicação aos estudos, fazendo com que ela tivesse uma profissão que não queria.

Eu acabei fazendo o normal porque a minha mãe quis, o meu pai era muito rigoroso, eu queria na época fazer computação e eu sempre fui CDF, muito estudiosa. Então, assim, eu sempre passava nos primeiros lugares eu sabia que eu ia entrar, ela não permitiu, na época pra mim foi muito complicado pra minha cabeça, porque eu ia ter uma profissão que eu não queria. (Professora Estrela).

A base afetivo-volitiva (VYGOTSKY, 2001) dessa professora, marcada pelos seus interesses e necessidades pelos estudos, sua vontade e motivação para a computação, não foi ouvida nem sentida pelos pais que definiram sua profissão, além de sua consciência. Entendendo que a consciência procede da experiência histórica e social. Portanto, o sujeito, à medida que participa e compartilha da experiência humana, convive com as experiências dos e nos outros para viver no plano psicológico a experiência "multiplex" (SMOLKA, 2004).

Essas três professoras trazem em suas trajetórias as marcas da não escolha pela profissão docente, que não são significadas apenas como experiências negativas nem escolhas equivocadas das mães, mas como processos que as constituíram professoras, apesar da não opção pela profissão docente. É interessante perceber como as narrativas funcionam como organizadoras das experiências vividas e produzem sentidos à própria vida dos entrevistados, como diz Bakhtin (1992b, p. 166), "pode dar forma à consciência, à visão, ao discurso, que terei sobre a minha própria vida”. 
Nesse turbilhão de produção de sentidos, com as circunstâncias e intercorrências, as mães continuam presentes nas escolhas dos filhos, mas às vezes são contrárias à opção pela Pedagogia. Uma das entrevistadas não fez magistério, uma vez que queria agronomia ou zootecnia, mas decidiu pela pedagogia. A escolha pela Pedagogia Educação Especial, no caso dessa Professora, está relacionada a uma experiência marcante que teve no ensino fundamental e que deixou vestígios no seu tom emocional-volitivo (BAKHTIN, 2010) e na sua base afetivo-volitiva (VYGOTSKY, 2001), definindo sua escolha e trajetória profissional para além da posição da sua mãe na trama familiar.

O que me levou a fazer a Pedagogia da Educação Especial, não que seja definitivamente só uma experiência que eu tive no quarto ano, na quarta série, mas aquilo me marcou muito. Não esqueço. $\mathrm{Na}$ escola que eu estudava a gente fez uma visita à $\mathrm{APAE}$, naquela época, né, e aquilo me marcou, era uma coisa que me interessava já, era uma coisa que assim me despertava atenção. Daí eu fui fazer Pedagogia voltada pra questão da Educação Especial. (Professora Rosa).

A compreensão do modo de pensar e de atuar pode estar relacionada ao subtexto (VYGOTSKY, 2001; MOLON, 2003), aos fragmentos (VYGOTSKY, 1995), aos indícios e sinais (GINZBURG, 1989), aos signos, aos registros residuais de experiências passadas, que ressoam, entoam, afetam, que persistem aos silêncios $\mathrm{e}$ às vozes, que residem nas brechas e nas ausências, que ressignificam memórias e constituem fenômenos psicológicos. Assim, pode-se verificar e questionar o quanto as escolhas, os valores, as questões de gênero e de classe social estão atravessando e influenciando na formação inicial e continuada dos professores.

\section{Experiência na sala de aula e a relação entre teoria e prática}

Um outro aspecto a ser debatido nos processos de constituição dos professores e nos seus modos de subjetivação é sobre a experiência na sala de aula durante a graduação e a relação entre teoria e prática na formação inicial e continuada.

O debate sobre a relação entre teoria e prática é longo e perpassa todas as áreas do conhecimento, sobretudo coloca em discussão os modelos de produção de conhecimento e os tipos de saberes reconhecidos e valorizados. Inúmeros autores já se debruçaram sobre isso e as contribuições e colaborações disputam as arenas e os palcos acadêmicos, as polêmicas demarcam espaços de poder e de conflitos de interesses e posições ideológicas. Sem a pretensão de dar conta desse cenário, procura-se compreender como os professores investigados elaboram e produzem sentidos para suas experiências em sala de aula e para a relação entre teoria e prática.

Uma das entrevistadas que fez magistério, e que teve várias experiências no estágio do magistério e atuou como monitora (era concursada para ser monitora) desde o início da graduação em Pedagogia, fala sobre a dificuldade profissional do ser professor, fato que questiona a função formativa do magistério. Essa professora ressalta que o processo de se tornar professor não é rápido, que a idade da pessoa pode in- 
fluenciar no seu desempenho profissional, diz que era muito menina aos 16 e 17 anos, trazendo o questionamento sobre as fases do desenvolvimento, a inserção no mundo do trabalho e a apropriação das condições históricas e concretas.

A discussão dos períodos ou etapas do desenvolvimento permite a superação das noções de linearidade temporal, continuidade e permanente evolução, entendendo o desenvolvimento "como um processo que inclui, simultaneamente, avanços e retrocessos, bem como ambiguidades, rupturas e descontinuidades" (OLIVEIRA, REGO; AQUINO, 2006, p. 119).

Nesse sentido, percebe-se os modos de inserção dos sujeitos em suas condições de vida (na história das relações sociais e intersubjetivas) e os múltiplos modos de apropriação de tais condições, principalmente dos que enfrentam situações financeiras adversas, como é o caso dos sujeitos entrevistados.

A procura pela experiência em sala de aula durante a graduação pode ter sido motivada por questões financeiras, tanto por dificuldades econômicas da família quanto pela busca do sustento para custear os estudos, como apontam três sujeitos. No entanto, outros dois também trabalharam durante a graduação, uma fazendo estágio na sua área de formação, que era a Educação Especial, e a outra em diversas atividades profissionais, até chegar à sala de aula.

Essas experiências relacionadas à atividade docente apresentam especificidades, para cada sujeito, que estão relacionadas aos motivos das escolhas feitas, às maneiras de fazer e aos modos de apropriação das condições concretas de vida (familiares e sociais).

Uma das professoras, que precisava trabalhar inclusive durante o magistério, diz que não tinha noção da profissão. É interessante observar na sua trajetória de formação seus processos de singularização marcados pelo que não foi, ou seja, não cursou terapia ocupacional nem enfermagem, porém, queria ser médica, mas decidiu prestar para enfermagem e disse para mãe que não tinha base para prestar para medicina. Como aponta Fontana (2000), o que não somos está em nós. Nesse sentido, a entrevistada fala sobre o que é (vivendo dialeticamente o que não é), sobre o modo como compreende e dá sentido à sua trajetória individual, bem como aponta as implicações sociais e culturais nos percursos individuais e nas escolhas feitas ou traçadas pelos outros, sobretudo pelos familiares.

Uma outra entrevistada que fez magistério também não se sentia preparada para a atividade docente. Percorreu vários empregos em diversos setores e voltou a estudar; começou a fazer Direito, cursinho e se encontrou no curso de Letras, dando aulas em dois períodos, no ensino fundamental e na Educação de Jovens e Adultos.

O drama de não se sentir preparada para a atividade docente vivido na trama de outras experiências possibilitou o entendimento do que gostava de fazer, a descoberta da diferença entre o aprender para si e o aprender para ensinar, e a tessitura da definição profissional. Assim, evidencia a percepção de diferentes modos de ensinar e de aprender, indicando momentos de tensão e de crise diante do que é oferecido como 
possibilidade de formação e de atuação e o que é vivido como necessidade de formação para se sentir em condições de atuar. Dessa maneira, por meio das implicações e repercussões de suas atividades fora do espaço escolar e de suas práticas docentes em três períodos, com os encantamentos e os desassossegos, foi se constituindo professora e vivenciando modos de subjetivação nessas relações intersubjetivas, em que os outros assumiram diferentes lugares e diversas posições sociais que influenciaram a sua posição e o seu papel social como educadora.

A relação entre teoria e prática faz lembrar que a significação não é imediata nem uma reação direta a uma determinada situação, ou seja, nada no sujeito é imediato. Tudo é mediado. As relações intersubjetivas fazem a mediação semiótica, fazem a conversão do plano interpsicológico no plano intrapsicológico, sem deixar de ser social, já que na conversão ocorre a superação e a mediação, a negação dialética, em que o social é a condição sine qua non do individual. Assim, os modos de subjetivação estão situados nas práticas históricas e sociais em que os sujeitos experimentam e se apropriam dos significados instituídos e convencionados e (re)constroem sentidos.

Outro aspecto que emergiu na fala de alguns entrevistados diz respeito ao discurso que não vale a pena, marcando os corpos cansados e formatados e as mesmices das práticas de alguns professores. Smolka (2006a, p. 108) diz que “... a sensibilidade orgânica e as sensações vão se tornando significativas, na medida em que os corpos/sujeitos se afetam e produzem efeitos/afetos uns nos outros...”. Portanto, cada corpo é constituído por relações internas entre os órgãos, por relações externas com os outros corpos e por afecções (objetivação e subjetivação de sujeitos em relação entre si, com o mundo e consigo mesmo). Sobre isso, Chauí (1995, p. 54-55) acrescenta que "qualquer corpo, enquanto singularidade dinâmica (como sistema complexo de movimentos internos e externos) e intercorpóreo, pressupõe e apresenta a intercorporeidade como originária".

Pelo que se pode acompanhar desse grupo de professores, todos resistem com astúcia a esse chavão - "que não vale a pena" - e estabelecem outras formas de conceber seus corpos e suas práticas cotidianas. O corpo é visto como transitório e provisório, que se torna distinto aos distintos e suas maneiras de fazer evidenciam astúcias sutis, táticas de resistência, modos de se reapropriar do espaço, do tempo, da história e dos recursos à sua maneira.

A busca pela formação continuada configura-se como uma tática de resistência que permite estabelecer novos vínculos e também fortalecer posições, ações e escolhas. A formação continuada desses professores aconteceu por meio de intensas experiências de vida, de grupos de estudos e de pesquisas dentro e fora do espaço institucional que orientam os seus trabalhos pedagógicos.

\section{Algumas considerações sobre a experiência da pesquisa}

A possibilidade de entrar, de participar e atuar nos meandros das relações intersubjetivas em um grupo de formação continuada em uma escola permite a intervenção no acontecimento, nas práticas cotidianas, nos modos de subjetivação das 
experiências. Além disso, possibilita compreender que os processos de constituição dos professores são complexos e permanentes, que os fragmentos e os indícios que se observam e nos quais se participam proporcionam reflexões e teorização, que podem fazer sentido para os sujeitos envolvidos e para outros que experimentam os desafios, os encantamentos e os desassossegos dessa profissão, que implica os processos formativos, quer seja o magistério, a pedagogia, as licenciaturas, quer seja a pós-graduação e a formação continuada.

O desafio proposto neste estudo persiste, pois se permanece indagando como os professores se apropriam e/ou resistem e/ou rejeitam as experiências vividas em suas práticas e em suas relações? Como significam suas experiências? Como compartilham sentidos? Como vivem seus dramas? Como se constituem e mutuamente constituem outros sujeitos? E como vão produzir sentidos a partir dessa experiência escrita e compartilhada? Compreendendo, conforme Smolka (2004, p. 44), que "a significação, como produção de signos e sentidos, é (resultante de) um trabalho coletivo em aberto, que implica ao mesmo tempo, acordo mútuo, estabilização, e diferença (inter-in-compreensão constitutiva...)".

Assim, a vida é movimento, a significação não é estática, unívoca, cristalizada em configurações subjetivas e pessoais, não é o resultado de um sujeito ou de um evento ou de uma ação. A significação é potência da experiência com outro, é afecção do signo, daquilo que se produz na relação com o outro, e encontra-se nas diversas e múltiplas relações intersubjetivas (relações com e entre outros sujeitos), nos modos de funcionamento e de atuação do outro e da linguagem nas práticas sociais que produzem sentidos.

Os processos de constituição dos professores aconteceram nas relações sociais e foram analisados por meio das narrativas das experiências de formação inicial e continuada, da atuação docente e dos meandros das relações intersubjetivas e das práticas cotidianas. Nessa trama da vida, os professores foram vivendo seus dramas no cotidiano do contexto escolar.

A tessitura dessa trama foi feita de significados instituídos que atravessam escolhas, valores, questões de gênero e de classe social na formação inicial, bem como de sentidos que foram forjados na vida, às vezes de modo discreto, peculiar, entediante, apaixonado, indignado, revoltado, etc., sobre a experiência em sala de aula e a relação entre teoria e prática.

Nas relações intersubjetivas, os professores experimentaram maneiras de fazer, modos de resistir, significaram relações de corpos, sujeitos e signos. Assim, os fragmentos das práticas cotidianas dos professores trouxeram muitas experiências, diversas situações e condições, várias posições e lugares sociais, a multiplicidade de tons emocionais volitivos, para além das presenças em sala de aula e nas reuniões na escola com o grupo de pesquisa, nas ausências e nos silêncios, definindo um espaço e um tempo impregnado de produção de sentidos.

Para finalizar, ressalta-se a importância de desenvolver ao mesmo tempo atividades de pesquisa e de extensão tanto para os pesquisadores quanto para os pro- 
fessores. Os professores, ao perceberem que os pesquisadores também estavam implicados em processos de ensinar e aprender e que eles também estavam se constituindo pesquisadores, trouxeram significativas reflexões para o espaço de formação continuada de todos os envolvidos no processo de intervenção e de investigação. É necessário continuar investindo e investigando nesses espaços de formação, pois é um processo complexo e repleto de contradições, que exige o enfrentamento constante de conflitos e superações, tensões e crises na e da dinâmica do e no cotidiano escolar.

\section{Referências}

AMORIM, M. Para uma filosofia do ato: "válido e inserido no contexto". In: BRAIT, B. (Org.). Bakhtin, dialogismo e polifonia. São Paulo: Contexto, 2009. p. 17-43.

BAKHTIN, M.; VOLOCHINOV, V. N. Marxismo e filosofia da linguagem. São Paulo, Hucitec, 1992a .

BAKHTIN, M. Estética da criação verbal. São Paulo: Martins Fontes, 1992b.

Para uma filosofia do ato responsável. São Carlos: Pedro \& João Editores, 2010.

CHAUI, M. Espinosa: uma filosofia da liberdade. São Paulo: Moderna, 1995.

FONTANA, R. C. Trabalho e subjetividade: nos rituais da iniciação, a constituição do ser professora. Cadernos Cedes, Campinas, n. 50, p. 103-119, 2000.

FRANCO, M. L. P. B. Análise de Conteúdo. Brasília: Liber Livro Editora, 2007.

GERALDI, J. W. A diferença identifica. A desigualdade deforma. Percursos bakhtinianos de construção ética e estética. In: FREITAS, M. T.; JOBIM E SOUZA, S; KRAMER, S. (Orgs.). Ciências humanas e pesquisa: Leituras de Mikhail Bakhtin. São Paulo: Cortez, 2003. p. 39-56.

GINZBURG, C. Mitos, emblemas, sinais: morfologia e história. São Paulo: Companhia das Letras, 1989.

GÓES, M. C. R. A abordagem microgenética na matriz histórico-cultural: uma perspectiva para o estudo da constituição da subjetividade. Cadernos Cedes. Campinas, n. 50, p. 9-25, 2000.

GÓES, M. C. R. e SMOLKA, A. L. B. (Orgs.). A significação nos espaços educacionais: interação social e subjetivação. Campinas: Papirus, 1997.

GÓES, M. C. R.; SMOLKA, A. L.; PINO, A. A constituição do sujeito: uma questão recorrente? In: WERTSCH, J.; DEL RIO, P.; ALVAREZ, A. (Orgs.). Estudos socioculturais da mente. Porto Alegre: Artes Médicas, 1998, p. 143-158.

MOLON, S. I. Subjetividade e constituição do sujeito em Vygotsky. Petrópolis: Vozes, 2003.

. As contribuiç̃ôes de Vygotsky na formação de educadores ambientais. In: LOUREIRO, Carlos F. B.; LAYRARGUES, Philippe P.; CASTRO, Ronaldo S. de. (Orgs.). Repensar a educação ambiental: um olhar crítico. São Paulo: Cortez, 2009.

OLIVEIRA, M. K.; REGO, T. C.; AQUINO, J. G. Desenvolvimento psicológico e constituição de subjetividades: ciclos de vida, narrativas autobiográficas e tensões da contemporaneidade. Pro-posições, Campinas, v. 17, n. 2 (50), p.119-138, 2006.

PINO, A. As marcas do humano: às origens da constituição cultural da criança na perspectiva de Lev S. Vigotski. São Paulo: Cortez, 2005.

. A produção do imaginário e a formação do sentido estético. Reflexões úteis para uma educação humana. Pro-posições, Campinas, v.17, n. 2 (50), p. 47-69, 2006. 
SMOLKA, A. L. B. Sentido e significação. Parte A - Sobre significação e sentido: uma contribuição à proposta de rede de significações. In: ROSSETTI-FERREIRA, M. C.; AMORIM, K. S.; SILVA, A. P. S.: CARVALHO, A. M. A. Rede de significações e o estudo do desenvolvimento humano. Porto Alegre: Artmed, 2004.

. Enseñar y significar: las relaciones de la enseñanza en cuestión. O de las (no) coincidencias en las relaciones de enseñanza. Cultura y Educación, Barcelona, v. 18, n. 1, p. 3-14, 2006a.

. Experiência e discurso como lugares de memória: a escola e a produção de lugares comuns. Pro-posições, Campinas, v. 17, n. 2 (50), p. 99-118, 2006b.

THOMPSON, E. P. A miséria da teoria ou um planetário de erros: uma crítica ao pensamento de Althusser. Rio de Janeiro: Zahar editores, 1981.

VYGOTSKY, L. S. Obras Escogidas: Vol. III. Problemas del desarrollo de la psique. Madrid: Visor Dis., S.A., 1995.

Teoria e método em psicologia. São Paulo: Martins Fontes, 1996.

Pensamento e linguagem. São Paulo: Martins Fontes, 1998.

Manuscrito de 1929. Educação \& Sociedade, Campinas, n.71, p. 21-44, 2000.

A construção do pensamento e da linguagem. São Paulo: Martins Fontes, 2001.

ZANELLA, A. V.; MOLON, S. I. Ressignificando corpos, saberes e fazeres: a formação docente em foco. In: ARANTES, E. M. M.; NASCIMENTO, M. L.; FONSECA, T. M. G. (Orgs.) Práticas PSI inventando a vida. Niterói, RJ: EdUFF, 2007.p. 53-64.

* Professora doutora da Universidade Federal do Rio Grande, Rio Grande, Rio Grande do Sul, Brasil.

\section{Correspondência}

Susana Inês Molon - Universidade Federal do Rio Grande, Departamento de Educação e Ciências do Comportamento, Coordenação de Pós-Graduação. Av. Itália, km 8, Carreiros, CEP: 96201-900, Rio Grande, Rio Grande do Sul - Brasil.

E-mail: susanamolon@vetorial.net

Recebido em 12 de setembro de 2015

Aprovado em 09 de dezembro de 2015 